\title{
Hubungan Efikasi Diri Pengasuhan Terhadap Kecemasan Orangtua Anak Dengan Autisme
}

\author{
Yasmin Meutia Solihati \\ Pascasarjana Magister Profesi Psikologi, Universitas Ahmad Dahlan \\ Email: meutiayasmin@gmail.com
}

\begin{abstract}
This research aims to determine the relationship between parenting self efficacy, and anxiety of parents with autism children. This study involved 41 parents aged 27 to 60 years old and had children autism with 5 to 12 years old. Anxiety scale, gratitude scale, parenting self efficacy scale, and social support scale was used to collect the data. This Research using the product moment method with IBM SPSS Statistic Version 22 to analyze the data. The results showed that there was a relationship between parenting self-efficacy on the anxiety of parents of children with autism with a value of $\mathrm{r}=0.257$ and $\mathrm{p}=0.000$.
\end{abstract}

Keywords: Anxiety, Autism, Parenting Self-Efficcay

\begin{abstract}
Abstrak
Penelitian ini bertujuan untuk menguji hubungan efikasi diri pengasuhanerhadap kecemasan orangtua anak dengan autisme. Subjek pada penelitian ini berjumlah 41 orangtua yang berusia 27 sampai 60 tahun dan memiliki anak autisme usia 5 sampai 12 tahun. Pengumpulan data menggunakan skala kecemasan, dan efikasi diri pengasuhan. Analisis data menggunakan metode product moment dengan menggunakan IMB SPSS Statistic Version 22. Hasil penelitian menunjukkan bahwa tedapat hubungan antara efikasi diri pengasuhan terhadap kecemasan orangtua anak dengan autisme dengan nilai $r=0,257$ dan $p=0,000$.
\end{abstract}

Kata Kunci: Autisme, Efikasi Diri Pengasuhan, Kecemasan

\section{Pendahuluan}

Autisme merupakan salah satu masalah gangguan perkembangan yang ditandai dengan terhambatnya kemampuan komunikasi, sosial dan perilaku [1]. Menurut Centre of Disease Control (CDC) pada tahun 2014 memperkirakan terdapat satu dari 59 anak di Amerika menyandang autisme. Prevalensi tersebut mengalami peningkatan setiap tahunnya, pada tahun 2016 diperkirakan terdapat satu dari 54 anak mengalami gangguan autisme [2]. Di Indonesia belum terdapat angka pasti mengenai prevalensi anak dengan gangguan autisme, akan tetapi menurut Incidence dan Prevalence Autism Spectrum Disorder (ASD), terdapat dua kasus baru yang muncul per 1000 penduduk dalam satu tahun dan 10 kasus per 1000 penduduk. Sementara penduduk Indonesia berjumlah 237,5 dengan pertambahan penduduk $1,14 \%$. Jika mengikuti perkiraan tersebut maka diperkirakan pada tahun 2018 terdapat 2,4 juta jiwa penyandang autisme dengan pertambahan penyandang baru sebanyak 500 jiwa pertahun [3]. Kehadiran anak autisme, mempengaruhi kehidupan keluarga, terutama orangtua. Hal ini dikarenakan kondisi anak autisme yang memiliki banyak keterbatasan membuatnya membutuhkan perhatian yang lebih dibanding anak lainnya. Tuntutan pengasuhan yang tinggi tersebut memicu munculnya tekanan dan permasalahan pada diri orangtua, seperti stres, kecemasan dan depresi [4]. Kecemasan merupakan salah satu masalah kesehatan mental yang dialami oleh orangtua ketika memiliki anak autis. Menurut Ogston, MacKintosh \& Myers (2011) kecemasan yang dirasakan oleh orangtua dengan anak autisme berkaitan dengan pendidikan, interaksi sosial, kesehatan, kemandirian, pekerjan di masa depan dan kehidupan rumah tangga anak. Kondisi tersebut sesuai dengan hasil diskusi yang dilakukan terhadap enam orangtua anak autisme pada tanggal 13 Januari 2020 di Pusat Layanan Autis Yogyakarta. Keenam orangtua mengungkapkan merasa cemas akan kondisi anak di masa depan, terutama ketika orangtua tidak dapat lagi mengurus anak karena faktor usia atau telah meninggal dunia. Kecemasan yang dirasakan oleh orangtua juga dipicu oleh kurang adanya penerimaan lingkungan terhadap kondisi anak autisme yang dianggap tidak normal. Berbagai kekhawatiran yang dirasakan oleh orangtua memicu timbulnya perasaan sedih maupun kesulitan untuk tidur ketika memikirkan mengenai kondisi anak.

Diterima Redaksi: 1-11-2020 | Selesai Revisi: 23-1-2021 | Diterbitkan Online: 24-1-2021 
Pada taraf yang ringan, kecemasan yang dialami oleh orangtua dapat membantu untuk waspada dalam mengambil suatu keputusan atau memperkecil bahaya yang akan terjadi, akan tetapi pada taraf tertentu kecemasan dapat menurunkan kemampuan persepsi dengan terus memusatkan perhatian pada suatu hal yang diaggapnya penting dan mengensampingkan hal lainnya. Kemampuan berpikir juga akan, menurun sehingga orangtua dengan kecemasan sulit untuk berpikir dari sudut pandang yang lain (Yusuf, Fitryasari \& Nihayati, 2015). Saat orangtua mengalami kecemasan, maka orangtua tidak dapat memfungsikan kemampuannya secara optimal dalam mengasuh anak, ini dikarenakan orangtua selalu dalam bayangan kekhawatiran mengenai apa yang akan terjadi pada anak. Hal ini dapat menjadi masalah, karena kondisi anak autisme membutuhkan keterlibatan dan dukungan dari orangtua guna meningkatkan perkembangan anak agar lebih memiliki keterampilan yang berguna di masa depan [7]. Oleh karena itu penting bagi orangtua dengan anak autis bahagia dan sehat secara mental maupun fisik karena akan berpengaruh terhadap pengasuhan dan kondisi anak.

Salah satu hal yang dapat berpengaruh terhadap kecemasan adalah keyakinan terhadap kemampuan yang dimiliki oleh orangtua. Keyakinan dapat membuat persepsi menjadi lebih positif sehingga memicu timbulnya motivasi dan perilaku adaptif [8]. Keyakinan dalam ranah pengasuhan disebut dengan efikasi diri pengasuhan. Menurut Coleman dan Karraker (2000) efikasi diri pengasuhan merupakan keyakinan orangtua terhadap kemampuan mereka dalam melaksanakan tugas pengasuhan dan mempengaruhi perkembangan anak. Orangtua yang meyakini bahwa dirinya mampu dalam melakukan pengasuhan dengan baik, melihat situasi yang mengancam sebagai suatu tantangan sehingga tetap tenang dan tidak khawatir dalam mengatasi permasalahan. Sebaliknya, orangtua yang merasa tidak mampu dalam melakukan pengasuhan cenderung memandang situasi sebagi suatu ancaman sehingga memunculkan kecemasan [8].

Berdasarkan permasalahan yang telah diuraikan sebelumnya, banyaknya keterbatasan yang dimiliki oleh anak autisme dan kompleksnya pengasuhan yang diberikan memberikan dampak psikososial tersendiri bagi orangtua. Efikasi diri pengasuhan dianggap memiliki hubungan terhadap kecemasan yang dialami oleh orangtua. Kondisi tersebut membuat peneliti tertarik untuk melakukan penelitian guna melihat hubungan efikasi diri pengasuhan terhadap kecemasan orangtua dengan anak autisme. Sehingga hipotesis yang diajukan dalam penelitian ini adalah ada hubungan negatif antara efikasi diri pengasuhan dan kecemasan orangtua anak autisme.

\section{Kecemasan}

Kecemasan merupakan suatu perasaan takut dan khawatir yang tidak menyenangkan (Davidson, Neale \& Kring, 2006). Kecemasan merupakan keadaan emosi yang dirasakan individu tanpa adanya objek yang spesifik (Stuart, 2013). Pandangan tersebut selaras dengan pendapat Calhoun dan Acocella (Safaria \& Saputra, 2009) yang mengungkapkan kecemasan adalah perasaan takut yang disertai dengan adanya peningkatan reaksi pada gerakan dan tindakan.

Calhoun dan Acocella (Safaria \& Saputra, 2009) mengungkapkan tiga aspek dari kecemasan, antara lain: a) emosional, digambarkan sebagai perasaan yang dirasakan oleh orangtua sebagai dampak dari suatu stimulus yang memunculkan kecemasan, seperti sedih, marah, malu.Contoh aspek emosional yang dirasakan oleh orangtua anak autisme ialah, orangtua merasa tegang saat memikirkan mengenai kehidupan anak di masa depan. Orangtua merasa sedih ketika anak belum menunjukkan perkembangan meskipun sudah melakukan terapi, b) kognitif, digambarkan sebagai perasaan khawatir yang mempengaruhi kemampuan berpikir. Contoh aspek kognitif yang dialami oleh orangtua anak autis ialah, orangtua tidak dapat berpikir mengenai hal-hal positif yang dapat dilakukan anak di masa depan. Orangtua tidak berdaya ketika ditanya mengenai perkembangan anak, c) fisiologis, digambarkan sebagai perasaan kahwatir yang disertai dengan munculnya rekasi tubuh, seperti detak jantung yang berdetak lebih cepat, tekanan darah meningkat. Contoh aspek fisiologis yang dialami oleh orangtua anak autisme ialah, orangtua mengalami kesulitan untuk tidur ketika memikirkan mengenai keterbatasan yang dimiliki oleh anak dan berpengaruh terhadap masa depan anak.

\section{Efikasi diri Pengasuhan}

Konsep efikasi diri pengasuhan berasal dari teori efikasi diri Bandura yang didefinisikan sebagai keyakinan indvidu terhadap kemampuannya untuk memenuhi atau mencapai tujuan tertentu [11]. Selanjutnya Coleman dan Karraker (2000) membuat suatu konstruk efikasi diri dalam ranah 
pengasuhan yang disebut dengan efikasi diri pengasuhan dan mendefinisikannya sebagai keyakinan orangtua terhadap kemampuan mereka dalam melaksanakan tugas pengasuhan dan mempengaruhi perkembangan anak. Efikasi diri pengasuhan merupakan penilaian orangtua terhadap kemampuan mereka dalam memberikan pengaruh positif bagi anak [12].

\section{Metode Penelitian}

Penelitian ini merupakan penelitian kuantitatif, dengan variabel independen berupa efikasi diri pengasuhan dan variabel dependen berupa kecemasan. Partisipan penelitian terdiri dari 41 orangtua dengan kriteria orangtua (ayah dan ibu) yang memiliki anak autisme usia 5 sampai dengan 12 tahun dan orangtua yang berusia 27 sampai dengan 60 tahun.

Alat ukur yang digunakan dalam proses penggalian data menggunakan skala kecemasan dan skala efikasi diri pengasuhan. Skala kecemasan orangtua yang digunakan memodifikasi skala kecemasan milik Wahyuningrum (2017) yang disusun berdasarkan aspek kecemasan menurut acuan Calhoun dan Acocella, aspek-aspek kecemasan orangtua tersebut antara lain aspek emosional, kognitif dan fisiologis. Sementara skala efikasi diri pengasuhan yang digunakan mengadaptasi dan memodifikasi skala milik Coleman dan Karraker (2000), dimensi-dimensi efikasi diri tersebut antara lain dimensi dicipline, achievement, recreation, nurturance dan health.

Analisis data yang digunakan dalam penelitian ini menggunakan analisis product moment. Perhitungan analisis data dilakukan dengan menggunakan komputer pada program Statistical Package for Social Science (SPSS) 22.0 for windows sebagai alat bantu analisis secara statistik.

\section{Hasil dan Pembahasan}

Hasil analisis menunjukkan skala kecemasan memiliki nilai reabilitas sebesar 0,952 dengan indeks beda aitem bergerak dari 0,373 hingga 0,905 . sementara skala efikasi diri pengasuhan memiliki nilai reliabilitas sebesar 0,891 dengan indeks beda aitem bergerak dari 0,261 hingga 0,722.

Selanjutnya dilakukan uji normalitas dan uji linearitas.

Tabel 1. Uji Normalitas

\begin{tabular}{lll}
\hline & Asymp. Sig. & \\
\hline Kecemasan & 0,593 & Keterangan \\
\hline Efikasi Diri Pengasuhan & 0,184 & Normal \\
\hline
\end{tabular}

Berdasarkan hasil uji normalitas yang telah dilakukan dapat disimpulkan bahwa ketiga data variabel memiliki sebaran data yang terdistribusi normal karena memiliki nilai Asymp.Sig > 0,05.

Tabel 2. Uji Linearitas

\begin{tabular}{ccccc}
\hline & & $\mathrm{F}$ & Sig. & Keterangan \\
\hline $\begin{array}{c}\text { Kecemasan* } \\
\text { Efikasi Diri Pengasuhan }\end{array}$ & $\begin{array}{c}\text { Deviation } \\
\text { from linearity }\end{array}$ & 1,173 & 0,382 & Linear \\
\hline
\end{tabular}

Berdasarkan hasil uji linearitas yang telah dilakukan dapat disimpulkan bahwa variabel efikasi diri pengasuhan memiliki hubungan linear dengan variabel kecemasan karena memiliki nilai Sig. $>0,05$. Setelah dilakukan uji normalitas dan uji linearitas, selanjutnya dilakukan uji hipotesis. Tujuan dilakukannya uji hipotesis ini adalah untuk mengetahui apakah ada hubungan antara efikasi diri pengasuhan dengan kecemasan.

Tabel 3. Uji Hipotesis

\begin{tabular}{llrll}
\hline Variabel & $\mathrm{r}$ & $\mathrm{r}^{2}$ & $\mathrm{p}$ & Keterangan \\
\hline $\begin{array}{l}\text { Efikasi diri pengasuhan } \\
\text { dengan Kecemasan }\end{array}$ & 0,506 & 0,257 & 0,000 & $\begin{array}{l}\text { Ada hubungan dan } \\
\text { sangat signifikan }\end{array}$ \\
\hline
\end{tabular}

Berdasarkan hasil analisis yang telah dilakukan, menunjukkan bahwa terdapat hubungan antara variabel independen terhadap variabel dependen, sehingga hipotesis penelitian dapat diterima. Hal ini dapat dikatakan terdapat hubungan negatif antara efikasi diri pengasuhan dengan kecemasan orangtua anak autisme. 
Kecemasan yang dirasakan oleh orangtua dapat memunculkan timbulnya kekhawatiran dan ketakutan dalam memandang kehidupan anak. Keyakinan yang dimiliki oleh orangtua untuk dapat melakukan pengasuhan dengan baik memicu timbulnya motivasi dan rasa optimisme untuk dapat mengasuh anak dengan optimal sehingga membantu perkembangan anak. Persepsi positif terhadap kemampuan orangtua tersebut ditunjukkan dengan tindakan pengasuhan yang adaptif, orangtua dapat membawa anak untuk melakukan terapi dan membantu anak di rumah dengan menyediakan bacaan atau permainan yang dapat menstimulasi perkembangan anak. Ketika anak sudah menunjukkan perkembangan yang baik, kecemasan yang dirasakan oleh orangtua akibat kondisi anak juga akan menjadi berkurang. Hasil ini mendukung penelitian sebelumnya yang dilakukan oelh [13] yang mengungkapkan terdapat hubungan antara efikasi diri pengasuhan terhadap kecemasan maupun depresi pada orangtua anak autisme. Orangtua dengan efikasi diri pengasuhan yang tinggi, akan terus berusaha untuk dapat melakukan pengasuhan sebaik mungkin sehingga berpengaruh terhadap perkembangan anak. Sementara orangtua dengan efikasi diri pengasuhan yang rendah, cenderung tidak yakin dengan kemampuannya sehingga mudah merasa cemas dan khawatir ketika menghadapi tantangan. Lebih dalam lagi (Junior, Celestino, Serra, Caron, \& Ponde, 2014) menjelaskan adanya perawatan terapi yang diterima oleh anak dapat meningkatkan perilaku adaptif anak autisme, akan tetapi perawatan tersebut tidak akan maksimal tanpa adanya pengasuhan yang baik dari orangtua. Orangtua yang yakin dengan kemampuannya akan paham mengenai kondisi dan cara menangani perilaku anak agar dapat berkembang lebih optimal. Kondisi tersebut yang dapat menurunkan kecemasan pada orangtua anak autisme.

\section{Kesimpulan}

Hasil penelitian yang dilakukan maka dapat disimpulkan bahwa terdapat hubungan negatif efikasi diri pengasuhan terhadap kecemasan orangtua anak autisme. Semakin tinggi tingkat efikasi diri pengasuhan, maka semakin rendah kecemasan yang dirasakan oleh orangtua anak autisme. Begitupun sebaliknya, semakin rendah tingkat efikasi diri pengasuhan, maka semakin tinggi kecemasan yang dirasakan oleh orangtua anak autisme. Berdasarkan hasil penelitian yang telah dilakukan tentang hubungan efikasi diri pengasuhan terhadap kecemasan orangtua anak autisme, maka peneliti memberikan beberapa saran yang diharapkan dapat bermanfaat, diataranya:

1, Bagi orangtua anak autisme, diharapkan dapat mempertahankan keyakinan diri terhadap kemampuannya dalam melakukan pengasuhan yang baik. Meskipun mengasuh anak autisme merupakan suatu tantangan, akan tetapi dengan keyakinan diri yang tinggi, orangtua akan berusaha untuk memaksimalkan usaha dalam melakukan yang terbaik untuk anak. 2, Bagi peneliti selanjutnya yang ingin meneliti dengan tema serupa diharapkan dapat menyeimbangkan jumlah responden antara ayah dan ibu sehingga perbedaan kecemasan antara ayah dan ibu dapat terlihat.

\section{Daftar Rujukan}

[1] American Psychiatric Association, American Psychiatric Association: Diagnostic and Statistical Manual of Mental Disorders Fifth Edition. 2013.

[2] Centers for Disease Control and Prevention, "Data \& Statistics on Autism Spectrum Disorder | CDC," CDC.gov, 2019. .

[3] Kemenkes RI, "Kenali dan deteksi dini individu dengan spektrum autisme melalui pendekatan keluarga untuk tingkatkan kualitas hidupnya," Kementrian Kesehatan Republik Indonesia, 2016. .

[4] W. Zhou, D. Liu, X. Xiong, H. Xu, and M. Manchia, "Emotional problems in mothers of autistic children and their correlation with socioeconomic status and the children's core symptoms," Med. (United States), vol. 98, no. 32, 2019.

[5] P. L. Ogston, V. H. MacKintosh, and B. J. Myers, "Hope and worry in mothers of children with an autism spectrum disorder or Down syndrome," Res. Autism Spectr. Disord., vol. 5, no. 4, pp. 1378-1384, 2011.

[6] N. Yusuf, Fitryasari, Buku Ajar Keperawatan Kesehatan Jiwa. Jakarta: Salemba Medika, 2015.

[7] N. Ramzan and K. Minhas, "Anxiety and depression in mothers of disabled and non-disabled children," ANNALS, vol. 20, no. 4, pp. 313-320, 2014.

[8] S. Nurlaila, "Pelatihan Efikasi Diri Untuk Menurunkan Kecemasan Pada Siswa-Siswi Yang Akan Menghadapi Ujian Akhir Nasional,” Guid. J. Ilmu Pendidikan, Psikologi, Bimbing. dan Konseling, vol. 1, no. 1, p. 1, 2011.

[9] P. K. Coleman and K. H. Karraker, "Parenting self-efficacy among mothers of school-age children: 
Conceptualization, measurement, and correlates," Fam. Relat., vol. 49, no. 1, pp. 13-24, 2000.

[10] T. \& N. S. Safaria, Manajemen Emosi: Sebuah Panduan Cerdas Bagaimana Mengelola Emosi Positif dalam Hidup Anda. Jakarta: PT Bumi Aksara, 2009.

[11] E. K. Hamovitch, M. C. Acri, and L. A. Bornheimer, "An analysis of the relationship between parenting self-efficacy, the quality of parenting, and parental and child emotional health," J. Fam. Soc. Work, vol. 22, no. 4, pp. 337-351, 2019.

[12] L. Kiang, T. Glatz, and C. M. Buchanan, “Acculturation Conflict, Cultural Parenting Self-Efficacy, and Perceived Parenting Competence in Asian American and Latino/a Families," Fam. Process, vol. 56, no. 4, pp. 943-961, 2017.

[13] L. K. Smart, "Parenting Self-Efficacy in Parents of Children with Autism Spectrum Disorders," 2016.

[14] P. Junior, Celestino, Serra, Caron, "Risk and protective factors for symptoms of anxiety and depression in parents of children with autism spectrum disorder," Dev. Neurorehabil., 2014. 